\title{
Article
}

\section{A Flow Visualization Study on the Mechanism of Turbulent Drag Reduction by Surfactants}

\author{
Takashi SAEKI*, Manuel R. De GuZMAN*, Hiroaki Morishima*, \\ Hiromoto USUI $^{* *}$, and Tatsuo NiSHIMURA ${ }^{* * *}$ \\ Department of Applied Chemistry and Chemical Engineering, \\ Yamaguchi University, Ube 755-8611, Japan* \\ Department of Chemical Science and Engineering, \\ Kobe University, Kobe 657-8501, Japan ${ }^{* *}$ \\ Department of Mechanical Engineering, \\ Yamaguchi University, Ube 755-8611, Japan ${ }^{* * *}$
}

(Received: May 17, 1999)

\begin{abstract}
Measurement of the velocity of a drag-reducing surfactant solution flow was carried out with the use of particle tracer velocimetry (PTV) to provide a better understanding of the mechanism of the drag reduction effect. From the results of the velocity data analysis, Reynolds stress is shown to be zero, but the turbulent intensity of the flow is still significant. The correlation between the two velocities at the pipe center and near the wall suggests that the flow of the drag-reducing surfactant solution is not a turbulent flow but some kind of a transitional flow. Such a transitional flow might include an intermittent laminar flow, which causes the Reynolds stress deficit.
\end{abstract}

Key Words: Surfactants/Drag reduction mechanism/Turbulence structure/Flow visualization

\section{INTRODUCTION}

Turbulent drag reduction (DR) is well known as an effective way of reducing the energy consumption in pipeline systems. Recently, drag reduction caused by surfactant solutions has been receiving much attention. In circulating flow systems, drag-reducing surfactant solutions do not undergo a permanent mechanical degradation, that is, the degradation of the surfactant micelles is reversible. Because of this property of surfactants, they are expected to be useful as drag-reducing additives in district heating and cooling systems.

The elucidation of the mechanism of the drag reduction effect is important for its application and developing new surfactants. Some researchers ${ }^{3,6), 14}$ suggested that the flow is controlled by the surfactant micelles. However, they cannot successfully explain the flow characteristics exhibited by dragreducing surfactant solutions. Several studies ${ }^{22,4,7,7,8), 10), 15)}$ dealt with the structure of turbulence in systems with drag-reducing surfactant additives. Most of them employed the method of the laser Doppler velocimetry (LDV) to measure velocities in turbulent flows. The advantages are that LDV is a non-contact technique, in which there is no measuring medium or device in direct contact with the flow, and that the response time is quick. Its disadvantage, however, is that the flow velocity measurement is only at one point at a time.

In this study, flow measurements for the DR effect were conducted through the method of the particle tracer velocimetry (PTV) to explain the mechanism of the surfactant drag reduction. The advantage of PTV is the possibility of a multiple-point measurement of the flow velocity in the axial and radial directions at a given time. The objective of this study is to provide insights into the mechanism of the DR effect occurring in drag-reducing surfactant solutions.

\section{EXPERIMENTAL}

Oleyl-bishydroxyethyl-methyl-ammonium chloride $\left(\mathrm{C}_{18} \mathrm{H}_{35} \mathrm{~N}\left(\mathrm{C}_{2} \mathrm{H}_{4} \mathrm{OH}\right){ }_{2} \mathrm{CH}_{3} \mathrm{Cl}\right.$, trade name: Ethoquad $\mathrm{O} / 12$, supplied by Lion Corporation, Japan), which has been reported to be an effective drag-reducing surfactant additive for cooling systems, was used in this work. Sodium salicylate (NaSal) was added as a counterion. The concentrations of Ethoquad O/12 and NaSal were $800 \mathrm{ppm}$ and $480 \mathrm{ppm}$, respectively. The experimental apparatus was a circulating pipeline system which included a head tank, a pump, a pressure drop test section, and a flow visualization section. The fluid temperature was fixed at $20^{\circ} \mathrm{C}$. The experiment was conducted with a $5-\mathrm{m}$ pipe with an inner diameter of $25 \mathrm{~mm}$. The pressure drop measurement was done by using a U-tube manometer filled with $\mathrm{CCl}_{4}$. The distance between the two taps of the manometer was $1.13 \mathrm{~m}$. Polyvinyl chloride (PVC) particles (diameter of a particle, $d_{p}=0.2 \mathrm{~mm}$ ), coated with a fluorescent paint, were used as tracer particles. Mikami et al. ${ }^{13)}$ also used almost the same particle size in their PTV measurements of a 
drag-reducing flow with a polymer solution. The specific gravity of the tracer particles was adjusted to that of the surfactant solution. The concentration of the particles in the solution was $10 \mathrm{ppm}$.

Fig.1 shows the details of the flow visualization section.

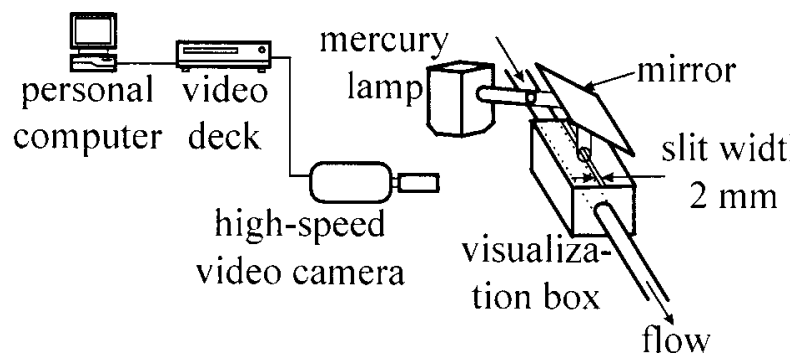

Fig. 1 Detailed drawing of flow visualization section

The pipe section at a point $4.5 \mathrm{~mm}$ from the inlet of the straight test section was illuminated through a 2-mm slit by using a high-pressure mercury lamp. The flow visualization image of the drag-reducing surfactant solution is shown in Fig. 2.

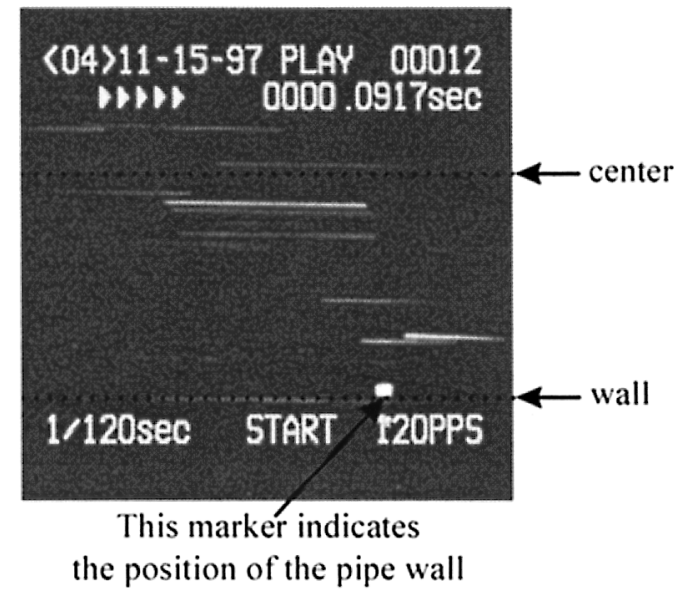

Fig. 2 Flow visualization image

The path lines by the tracer particles in the solution are shown as white lines under a shutter speed of 1/120 sec. These were recorded with a high-speed camera (FASTCAM, Photron Co., Ltd.), and the video image thus obtained was taken to a computer (PC-9801BX2, NEC Corporation). Then, the axial $\left(u_{i}\right)$ and radial $\left(v_{i}\right)$ velocity data were accumulated by hand on the monitor. These accumulated data were based on a total of 16,000 data obtained within the region between the pipe wall and its centerline. This region (as shown in Fig. 2) was subdivided into 20 blocks, with the data size of 800 in each block. The data in each block was averaged to obtain the timemean axial and radial velocities.
The definitions of average velocity, fluctuating velocity, turbulent intensity ( $T I)$, and Reynolds stress are given as follows:

$$
\begin{gathered}
u=\frac{\sum_{i=1}^{N} u_{i}}{N}, \quad v=\frac{\sum_{i=1}^{N} v_{i}}{N} \\
u_{i}^{\prime}=u_{i}-u, \quad v_{i}^{\prime}=v_{i}-v \\
T I, u=\frac{\sum_{i=1}^{N} \sqrt{u_{i}^{\prime 2}}}{N \cdot u^{*}}, \quad T I, v=\frac{\sum_{i=1}^{N} \sqrt{v_{i}^{2}}}{N \cdot u^{*}} \\
\text { Reynolds stress }=\frac{-\rho \sum_{i=1}^{N} u_{i}^{\prime} v_{i}^{\prime}}{N}
\end{gathered}
$$

where $u[\mathrm{~m} / \mathrm{s}]=$ time-mean axial velocity, $v[\mathrm{~m} / \mathrm{s}]=$ timemean radial velocity, $u_{i}^{\prime}[\mathrm{m} / \mathrm{s}]=$ fluctuating velocity in the axial direction, $v_{i}{ }^{\prime}[\mathrm{m} / \mathrm{s}]=$ fluctuating velocity in the radial direction, $N[-]=$ total number of data, $T I, u[-]=$ axial turbulent intensity, $T I, v[-]=$ radial turbulent intensity, and $u^{*}[\mathrm{~m} / \mathrm{s}]=$ friction velocity, with $u^{*}=\sqrt{\tau_{w} / \rho}$ and $\left(\tau_{w}[\mathrm{~Pa}]=\right.$ wall shear stress $(=\Delta P \cdot D / 4 L)$, where $\left(\rho\left[\mathrm{kg} / \mathrm{m}^{3}\right]=\right.$ density, $(\Delta P[\mathrm{~Pa}]=$ measured pressure drop across the test section, $D[\mathrm{~m}]=$ pipe diameter, and $L[\mathrm{~m}]=$ distance between the two taps of the manometer.

\section{RESULTS AND DISCUSSION}

From the results of the pressure drop measurements, the friction factor vs Reynolds number relationship was obtained, as shown in Fig. 3. Here, Reynolds number $\left(R e_{s}\right)$ was calculated based on the viscosity of the solvent (water). The drag reduction caused by the surfactant solution increased with Reynolds number and reached the maximum point at $R e_{s}=$ $5 \times 10^{4}$. When the Reynolds number was further increased, the drag reduction was lost rather abruptly. This phenomenon may be caused by the breakup of the surfactant micelle structures due to high shear.

To quantify the drag reduction, we introduce the parameter drag reduction percent:

$$
D R \%=\frac{f_{w}-f_{D R}}{f_{w}} \times 100
$$

where $f_{w}[-]=$ friction factor for water and $f_{D R}[-]=$ friction factor for a drag-reducing flow. Thus, the maximum $\mathrm{DR} \%$ was $66 \%\left(f_{D R}=0.002[-]\right.$ at $\left.R e_{s}=5 \times 10^{4}[-]\right)$. The following results, with the use of PTV, were obtained at $R e_{s}=27900$ [-] at which the DR\% was $56 \%$.

The average velocity distributions in the axial direction, both for water and the drag-reducing surfactant solution, are shown in Fig. 4.

The ordinate is the ratio of the time-mean axial velocity $(u$ 


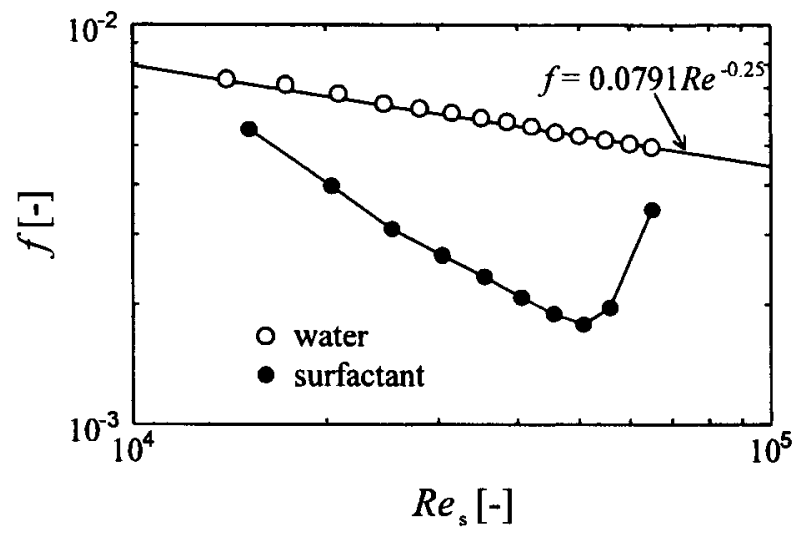

Fig. 3 Results of friction factor measurements

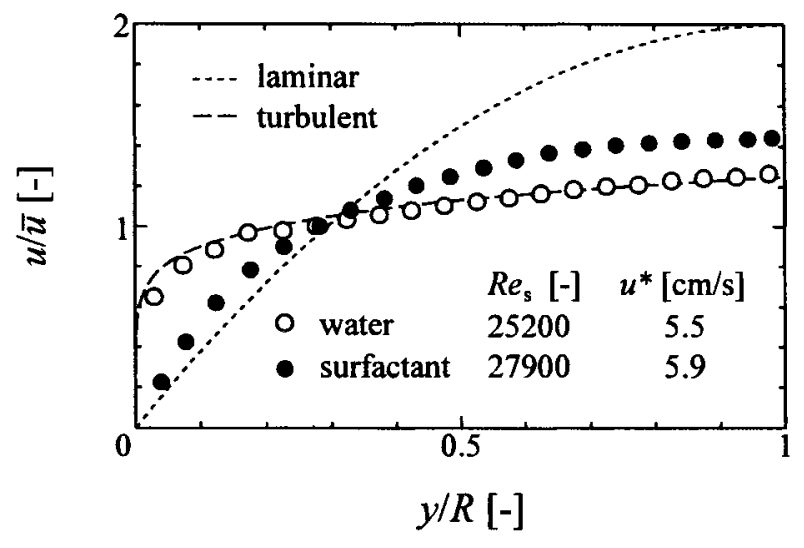

Fig. 4 Time-mean axial velocity profiles

$[\mathrm{m} / \mathrm{s}])$ to the cross-sectionally averaged time-mean velocity $(\bar{u}[\mathrm{~m} / \mathrm{s}])$. The abscissa is the dimensionless radial coordinate $y / R[-]$, where $y[\mathrm{~m}]$ is the radial coordinate measured from the wall and $R[\mathrm{~m}]$ is the pipe inner radius. Fig. 4 also includes two curves that represent the velocity distributions for a laminar and a turbulent flow of a Newtonian fluid. The water data fit well the turbulent flow curve. For the surfactant system, its velocity distribution lies between the two curves. The dragreducing surfactant flow, therefore, can be considered to be neither laminar nor turbulent.

Fig. 5 shows the turbulent intensities both for water and the surfactant solution at the same Reynolds numbers as in Fig. 4.

The ordinate is the axial or radial turbulent intensity, whereas the abscissa is the dimensionless coordinate $y^{+}[-] \quad(=$ $y u^{*} / v$, where $v\left[\mathrm{~m}^{2} / \mathrm{s}\right]$ is kinematic viscosity). The friction velocity $\left(u^{*}\right)$ for water $(=5.5[\mathrm{~cm} / \mathrm{s}])$ is comparable to that for the drag-reducing surfactant solution $(=5.9[\mathrm{~cm} / \mathrm{s}])$. As compared to the water data, the surfactant solution data show reduced turbulent intensities. For the surfactant solution flow, the intensity of the $u$ fluctuation is high and that of the $v$ fluctuation is low but nonzero.

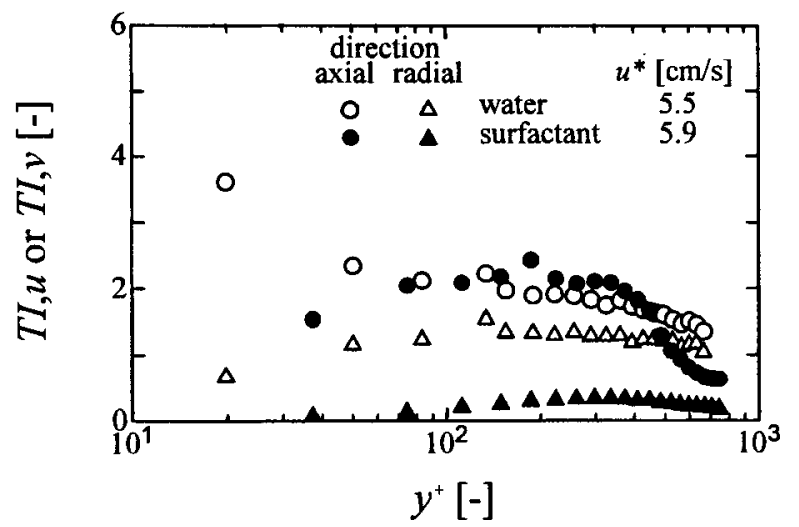

Fig. 5 Turbulent intensity distributions of axial $(u)$ and radial $(v)$ fluctuating velocities

The results of the Reynolds stress measurements are indicated in Fig. 6. The diagonal line represents the total stress distribution due to flow through a pipe. It is shown that the data for water satisfactorily coincide with the values calculated by the following equation:

$$
-\frac{\overline{u^{\prime} v^{\prime}}}{u^{* 2}}=1-\frac{y}{R}-\frac{v(\bar{u} / \partial y)}{u^{* 2}}
$$

Kawaguchi et $a l .{ }^{10)}$ and Hoyer and $\mathrm{Gyr}^{7)}$ measured the Reynolds stress in the drag-reducing flow with a surfactant by using LDV, and reported that it was almost zero. The same result was obtained in this work with the use of PTV. Based on the results (a zero Reynolds stress and a low but nonzero intensity of the $v$ fluctuation) obtained from this study, a nonReynolds stress momentum transfer mechanism should be considered.

In the so-called 'Reynolds stress deficit', the sum of the actual measured value of the Reynolds stress and the laminar momentum transfer does not show a linear distribution. This phenomenon was first observed in the drag-reducing flow with polymer solutions, for which the Reynolds stress is not zero. Several researchers, $\left.\left.\left.\left.{ }^{1)}, 5\right), 6\right), 9,12\right), 17 \sim 19\right)$ most of whom took account of the rheological properties of polymer solutions, gave suggestions to explain the mechanism of the dragreducing polymer solution flow. Berman ${ }^{1)}$ conducted a stress analysis using the FENE (finitely extendable nonlinear elastic) dumbbell model. He suggested that the elasticity of the polymer solution was a contributory factor to the Reynolds stress deficit. Massah and Hanratty ${ }^{12)}$ reported similar result as Berman. ${ }^{1)}$ Usui et $a l .{ }^{18)}$ measured the extensional viscosity of a polymer solution. They were able to explain a certain degree of momentum transfer by estimating the energy discharged at different radial positions from the elastic energy stored in the polymer solution. However, based on their estimated value, the Reynolds stress deficit cannot be explained completely. In a study by Kajishima and Miyake, ${ }^{9}$ a DNS (direct numerical 
simulation) for a multiple bead-spring dumbbell model was employed to examine the DR effect. Arbitrary elastic and viscoelastic parameters were used in their estimation. Their results did not show a significant $\mathrm{DR}$ effect (maximum $D R=$ $15 \%$ ).

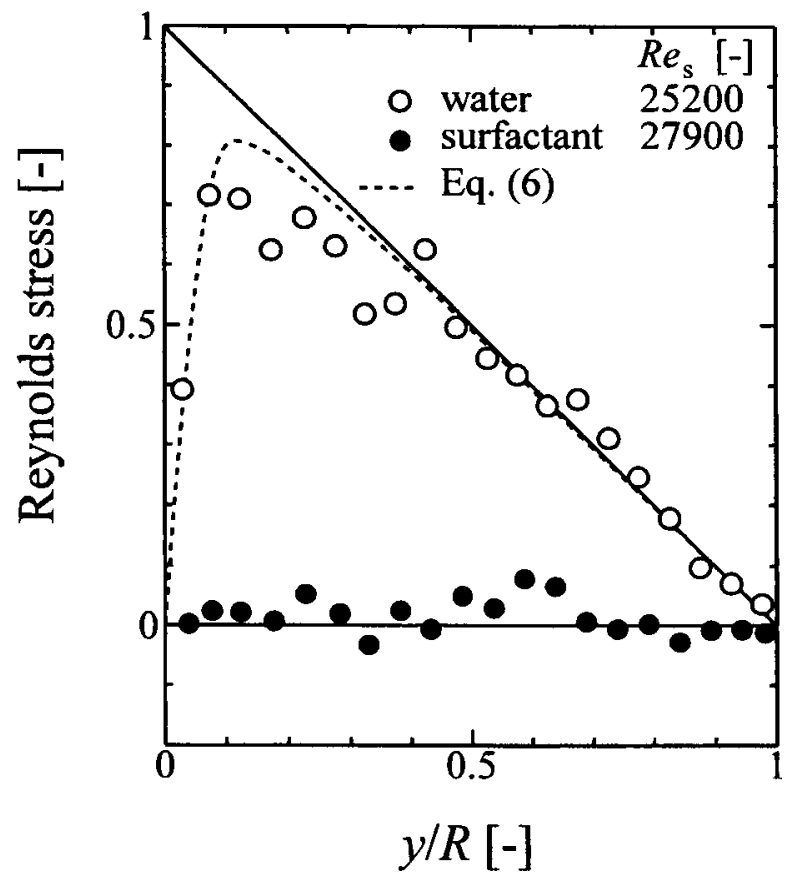

Fig. 6 Results of Reynolds stress measurements

From the above-mentioned previous work on the dragreducing polymer solution flow, it was indicated that a certain degree of momentum transfer due to the fluid elasticity affected the Reynolds stress deficit. However, such a discussion did not succeed in explaining the mechanism of the drag reduction. The foregoing investigations took into account the rheological properties in their consideration of the dragreducing system. But still, those were not successful. Nevertheless, they provide basic information for surfactant drag reduction.

Again from our experimental results, the Reynolds stress was demonstrated to be zero, which suggests that the flow is like a laminar flow. However, since the fluctuation of the streamwise velocity component is clearly observed in Fig. 5, the existence of a turbulence slug could be imagined. Hence, we considered that the flow is neither "turbulent" nor "laminar", and assumed that it is some kind of a "transitional flow". This concept has been the basis of the following to explain the drag-reducing flow.

The term "transitional flow" referred to in this study means that if the flow is transitional and if we look closely at the flow through a window fixed to a pipe, we would observe alternating flows of laminar and turbulent regions. Each region could be imagined to occupy the whole radial portion in the pipe. Here, the turbulent region is equivalent to a turbulent slug introduced by Lindgren. ${ }^{11)}$ We would then find out that with the occurrence of a laminar region, the fast average flow velocity is observed at the pipe center, in contrast to the slow average flow velocity observed near the pipe wall.

To confirm this alternating occurrence of a laminar flow and a turbulence slug, an analysis is made of the distribution of the axial local velocity near the wall $\left(u_{1}[\mathrm{~m} / \mathrm{s}]\right)$ and that in the neighborhood of the center of the pipe $\left(u_{2}[\mathrm{~m} / \mathrm{s}]\right)$, as shown in Fig. 7.

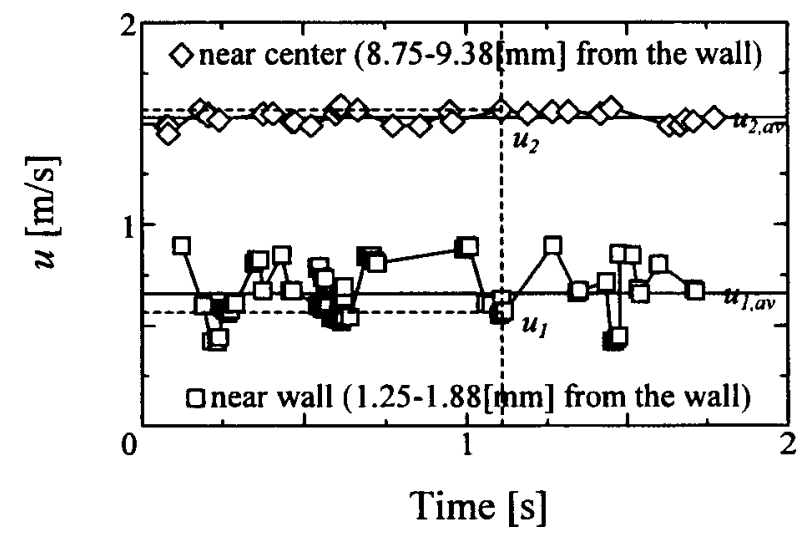

Fig. 7 Axial local velocity distributions

Such a set of data can be obtained by PTV, but not by LDV. If we let $u_{1}^{\prime}$ be the fluctuation velocity at a certain point near the pipe wall and $u_{2}^{\prime}$ be the one at a certain point in the vicinity of the pipe center, the product of these two values would be negative when the condition of either a laminar flow or a turbulence slug occurs. For example, from the local velocity distributions in Fig. 7, at a time $t=1.11$ [s]:

$$
\begin{aligned}
& u_{1}=0.57[\mathrm{~m} / \mathrm{s}] \\
& u_{2}=1.57[\mathrm{~m} / \mathrm{s}]
\end{aligned}
$$

By using Eq. (1), the average of the local velocities near the wall and that near the center were calculated respectively as:

$$
\begin{aligned}
& u_{1, \text { av }}=0.66[\mathrm{~m} / \mathrm{s}] \\
& u_{2, \text { av }}=1.53[\mathrm{~m} / \mathrm{s}]
\end{aligned}
$$

Then, by using Eq. (2), $u_{1}^{\prime}$ and $u_{2}^{\prime}$ were computed as follows:

$$
\begin{aligned}
& u_{1}^{\prime}=u_{1}-u_{1, \text { av }}=0.57-0.66=-0.09[\mathrm{~m} / \mathrm{s}] \\
& u_{2}^{\prime}=u_{2}-u_{2, \text { av }}=1.57-1.53=0.04[\mathrm{~m} / \mathrm{s}]
\end{aligned}
$$

Thus, the product of $u_{1}^{\prime}$ and $u_{2}^{\prime}$ was determined to be negative.

The result of the assumed alternating flow occurrence is 


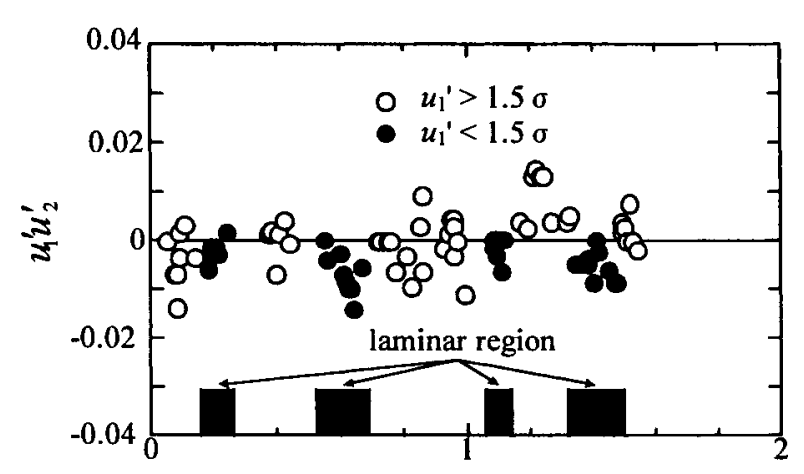

Time $[\mathrm{s}]$

Fig. 8 Correlation of pipe near-wall and central-part fluctuating velocities

shown in Fig. 8.

In this figure, filled circles show $u_{1}^{\prime}$ data that are less than 1.5 times the standard deviation of the fluctuating velocity, $\sigma$.This criteria means that the near-wall profile should be considered close to a laminar flow velocity distribution. It is clear that the most of filled circles cover the negative region, and as mentioned above, these results suggest that a laminar flow sometimes occurs. Here, from the finiteness of the tracer particle size, it was impossible to narrow down the widths of the blocks, especially near the wall. It was estimated that at the second near wall block (1.25-1.88 mm), where the velocity profile showed steep slope, the difference between the average velocity at the center of the block and those of the two edges was around $\pm 15 \%$. To take into account of this error, however, it is pointed out that four laminar regions can clearly exist in Fig. 8. Let the region covered by filled circles be defined as laminar and the other region as turbulence slug. Then, the time period (an average of $0.14[\mathrm{~s}]$ ) and the rate (approximately every other $1 / 5$ of a second) of the laminar flow region occurrence, which are indicated in Fig. 8, are represented as a

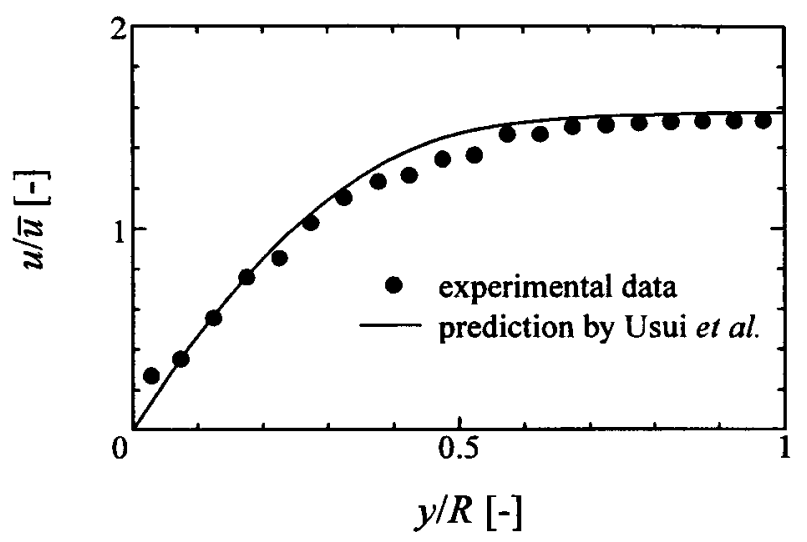

Fig. 9 Comparison of average velocity distribution for time zone regarded as laminar region with estimated result mean velocity profile in Fig. 9. In this figure, the velocity distribution predicted by Usui et $a l .{ }^{16)}$ for a drag-reducing surfactant solution flow is shown as a solid curve, which was obtained by considering the non-Newtonian properties of the surfactant solution. From the comparison of the average velocity distributions in Fig. 9, our calculated velocity distribution shows a satisfactory agreement with the estimated values.

It can be considered, therefore, that the region covered by filled circles shown in Fig. 8 is verified to be a laminar flow. In this study, even the turbulence slug region was not clearly extracted, we can say that the DR flow is some kind of a transitional flow. It is interpreted that the transition to a complete turbulent flow is at the disappearance of the DR effect observed in drag-reducing systems at a high Reynolds number. The transition flow is a result of the disturbance occurring in the state of a laminar flow. This disturbance does not affect the whole pipe flow. It can be said, however, that such a condition occurring in the flow is confined within a certain limited space.

The approach suggested in this study may provide better understanding for the phenomenon of a zero Reynolds stress.

\section{CONCLUDING REMARKS}

The flow characteristics of a drag-reducing surfactant solution were measured by using PTV to study the mechanism of the DR effect. It was found that the intensity of the fluctuation in the axial direction was high. However, the intensity of the fluctuation in the radial direction was low but nonzero. Despite the fluctuations occurring in the dragreducing surfactant solution flow, the Reynolds stress was shown to be zero. In this study, an assumption was made that the flow is not a "turbulent flow" but some kind of a "transitional flow", and this was confirmed from the resulting experimental data. However, further discussion is needed to clarify the mechanism of the DR effect.

\section{References}

1) Berman NS, "Drag Reduction in Fluid Flows", Sellin RHJ and Moses RT ed, (1989) Ellis Horwood Pub, p21.

2) Bewersdorff HW, Ohlendorf D, Colloid \& Polymer Sci, 266, 941 (1988).

3) Bewersdorff HW, Thiel H, Applied Scientific Research, 50, 347 (1993).

4) Chara Z, Zakin JL, Severa M, Myska J, Experiments in Fluids, 16, 36 (1993).

5) Gampert B, Rensh A, FED-Vol 237 ASME 1996 Fluids Eng Div Conf, 2, 129 (1996). 
6) Gyr A, Bewersdorff HW, "Drag Reduction of Turbulent Flows by Additives", (1989) Kluwer Academic Publishers, Dordrecht, The Netherlands.

7) Hoyer KW, Gyr A, Transactions of the ASME, 120, 818 (1998).

8) Itoh M, Imao S, Tokuda K, Nippon Kikaigakkai Ronbunshu (B), 61, 266 (1995).

9) Kajishima T, Miyake Y, J Mech Eng of Japan, 97, 1534 (1997).

10) Kawaguchi Y, Tawaraya Y, Yabe A, Hishida K, Maeda M, FED-Vol 237 ASME 1996 Fluids Eng Div Conf, 2, 45 (1996).

11) Lindgren, ER, Archiv for Fysik, 24, 269 (1963).

12) Massah H, Hanratty TJ, FED-Vol 237, 1996 Fluids Eng Div Conf, 2, 183 (1996).
13) Mikami F, Nishikawa N, Tanaka T, Proc of the 28th Turbulent Symp, 103 (1996).

14) Ohlendorf D, Interthal W, Hoffmann H, Rheol Acta, 25, 468 (1986).

15) Sato K, Mimatsu J, Kumada M, Thermal Sci \& Eng, 7, 41 (1999).

16) Usui H, Sakai R, Kagaku Kogaku Ronbunshu, 22, 221 (1996).

17) Usui H, Maeguchi K, Sano Y, Phys Fluids, 31, 2518 (1988).

18) Usui H, Sakuma Y, Saeki T, Proc of the 9th Symp on Turbulent Shear Flows, 20, 1 (1993).

19) Willmarth WW, Wei T, Lee CO, Phys Fluids, 30, 933 (1987). 